\title{
SIR WILLIAM MACEWEN (1848-1924)
}

\section{An Eponymic Centennial Note}

A century has gone full circle since Sir William Macewen was born on June 22, 1848, and yet his huge personality continues to overpower our generation. In the history of bone and joint surgery his name will forever be eponymously honoured through his operation which marks but one aspect of his life-long interest in bone problems. His classic monograph, "Osteotomy with an Inquiry into the Aetiology and Pathology of Knock-Knee, Bow-Leg, and other Osseous Deformities of the Lower Limbs," published in 1880 at the early age of thirty-two, is a succinct, lucid, comprehensive presentation of the subject, with the accent of finality on every page. Translated into many languages, it spread his fame throughout the civilised world. This extract is characteristic of the style:-

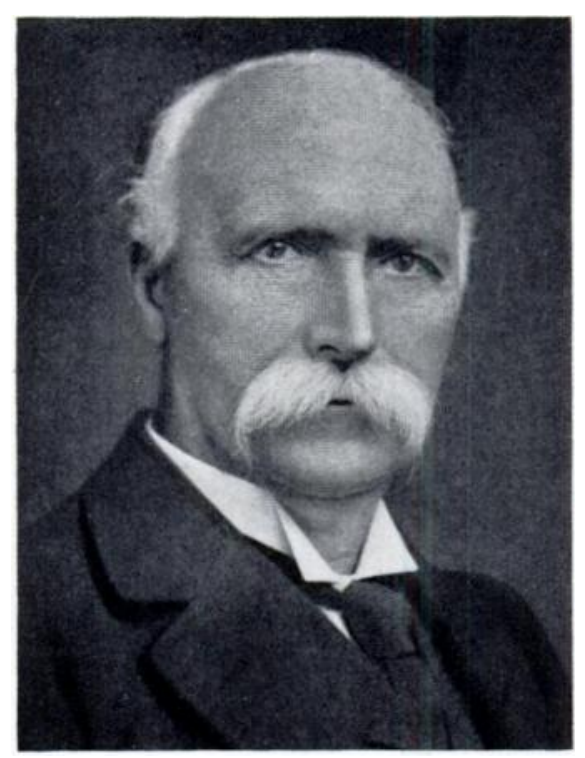

“ On April 11th, 1875, I performed antiseptic osteotomy on a girl, six years of age, who had osseous anchylosis of the right knee, following suppuration of the joint, rising as a sequela of scarlet fever. The limb was straightened, and the wound healed as a typically antiseptic wound does. This was the first case of osteotomy performed in Britain. The second was performed by Lister during the winter session 1875-76. . . A Antiseptic osteotomy was performed for the first time in London by Mr Barwell (Richard Barwell, F.R.C.S., Surgeon to Charing ('ross Hospital) on December 2nd, 1876. During the last few years antiseptic osteotomy has been greatly extended, and it has met with such success as to ensure it a permanent place as a safe, certain, and most successful procedure." (p. 62.)

The following extracts may be quoted from his "Clinical Lecture on Antiseptic Osteotomy: Having Special Reference to the Kind of Instruments Used, and to the Surgical Anatomy of the ExtraArticular Operation by Simple Incision at the Lower End of the Femur for Genu Valgum, delivered at the Glasgow Royal Infirmary." 1

"In this morning's remarks references will be made, among other points, to the following: the age suitable for such operations; the kind of instruments employed, and how to use them; and the surgical anatomy of the site selected for my operation of simple femoral incision in genu valgum. . . The chisel ought to be made to suit the material upon which it is to act. . . It ought to be made of very fine steel, tempered so as to prevent brittleness or too great softness. . . To employ a single word which would at once distinguish it from the ordinary chisel and at the same time be more euphemistic to a patient's ear, it might be called an ostcotome."

The first set of osteotomes was made in $\mathbf{1 8 7 6}$ by T. H. MacDonald, a blacksmith of Glasgow, under Macewen's direct supervision. The instrument was forged in a single piece and highly polished, at a time when bone-handled scalpels and wooden-handled chisels were universally employed, for Macewen had clearly grasped the principles of aseptic surgery.

Sir William Macewen's was a magnificent figure, with chiselled features and piercing grey eyes. His voice was low and mellow and, even when lecturing, hardly raised. He had an intense dislike to be photographed. A difficult character, he was essentially an individualist, unwilling or unable to share his ideas with colleagues or juniors; and he failed to win the affection of those who were his most devoted disciples.

W. R. Bett.

\footnotetext{
1 British Medical Journal, 1879, 1, 656-658.
} 